\title{
Comparative Study of Surgical Outcome of Chronic Subdural Hematoma Treated with and without External Drainage
}

\author{
Suresh Sapkota $^{1}$, Kiran Niraula ${ }^{2}$, Subash Lohani ${ }^{1}$, Shikher Shhrestha ${ }^{1}$, Bibhusan Shrestha ${ }^{1}$, Ashraf \\ Shaheen $^{3}$ \\ ${ }^{1}$ Department of Neurosurgery \\ Upendra Devkota Memorial National Institute of Neurological and Allied Sciences, Bansbari, Nepal \\ ${ }^{2}$ Department of Neurosurgery \\ ADK Hospital, Maldives \\ ${ }^{3}$ Department of Neurosurgery \\ King Edward Medical University, Lahore, Pakistan \\ Correspondence: \\ Dr. Suresh Sapkota \\ Department of Neurosurgery, Upendra Devkota Memorial National Institute of Neurological and Allied \\ Sciences, Bansbari, Nepal \\ Email: sapkota.suressh@gmail.com \\ Phone: +9779841311813
}

\begin{abstract}
Background and purpose: Chronic subdural hematoma (cSDH) poses a significant morbidity and mortality risk particularly in elderly population. It can be treated with simple surgical techniques like burr hole drainage under local anesthesia, however it often recurs after surgical evacuation in significant number of patients. Material and methods: A randomized controlled trial was designed at Mayo Hospital/KEMU in 2013 to 2016. Total number of 98 patients who met the inclusion and exclusion criteria were randomized into 'with drain' and 'without drain' arm. All of them were treated with burr hole drainage under local anesthesia. Half of them had subdural drain while the remaining half did not. Recurrence of hematoma and surgical outcome was compared. Result: Among 98 patients included in the study(54 males and 44 females) met the inclusion criteria. Mean age of presentation was 63 years \pm 12.4 (range 40-100). There was left sided preponderance in hematoma location (53.1\%). Mean midline shift was $2.7 \mathrm{~mm} \pm 1.5$. Owing to drainage of cSDH, post-operative MRC score of patients along with midline shift in the CT brain showed statistically significant improvement. However, irrespective of insertion of drainage system, there was no significant difference noted in recurrence of $\mathrm{cSDH}$, midline shift and improvement in presenting symptoms (hemiparesis or monoparesis) considering all post-operative days. Conclusion: There is no significant difference in recurrence rate depending on weather a postoperative external drainage is placed or not.
\end{abstract}

Keywords: Chronic Subdural Hematoma, Drain, Recurrence

$\longrightarrow$ hronic subdural hematoma (cSDH) poses a serious morbidity and mortality risk annual incidence of chronic subdural hematoma has been reported to be $1-5.3$ cases per 100000 population. ${ }^{1}$ Though liquefied cSDH are commonly treated with burr hole drainage, it is faced with recurrence rate ranging from5\%-33\%. ${ }^{2-4}$ Treatment for this entity has longtime remained controversial regarding the use of postoperative subdural drain. ${ }^{4-6}$ Although several authors have advocated the use of drainage to reduce the recurrence of $\mathrm{cSDH}$, there have been only few attempts to clarify this question with prospective studies. Hence, this study attempts to compare the recurrence of a $\mathrm{cSDH}$ after burr 30

Date submitted: 5/ 11/2019

Date accepted: 15/12/2019 hole drainage with and without the use of a postoperative subdural drain.

\section{Material and Methods}

A prospective randomized controlled trial was conducted at Mayo Hospital/KEMU in 2015/2016 with inclusion and exclusion criteria as follows:

\section{Inclusion Criteria}

1. Willing to participate (who gave consent or whose patient party gave consent for).

2. Patients with $\mathrm{CSDH}$ requiring burr hole evacuation admitted through outdoor and emergency.

egneuro Volume 02, Issue 01, 2020 DOI: https://doi.org10.3126/egn.v2i1.27459 
3. Patient of both sexes in the range of age $18-80$ years.

4. Chronic subdural hematoma with midline shift of more than $5 \mathrm{~mm}$ on CT scan.

\section{Exclusion criteria}

1. Patients with CSDH requiring surgical treatment other than burr hole evacuation.

2. Bilateral chronic subdural hematoma on CT scan.

3. Patients who underwent an operation for drainage of an ipsilateral CSDH within six months prior to admission confirmed from patient record.

4. Patients with CSF shunt in-situ confirmed from patient record and CTscan.

5. Patients with deranged bleeding and clotting profile.

Ninety-eight patients who met the criteria were randomized into 'with drain' and 'without drain' arm. All of them were treated with burr hole aspiration under local anesthesia. Primary outcome measure was recurrence of hematoma. Secondary outcome measures were improvement in MRC scores and midline shift.

SPSS verion 20 was used for data analysis and $\mathrm{p}$ value less than 0.05 was considered statistically significant.

\section{Results}

Over the period of two years, ninety-eight patients met the inclusion criteria. Half of them $(n=49)$ were treated with burr hole drainage with postoperative subdural drain and the other half with burr hole drainage only. There were $55.1 \%(n=54)$ male patients and $44.9 \%(n=44)$ female patients. Mean age of presentation was $63 \pm 12.4$ years (range 40-100). Pre-operative Glasgow Coma Scale (GCS) of the patients was $11.7 \pm 2.3$ (range $5-15$ ). $53.1 \%(\mathrm{n}=52)$ of the hematoma were located on the left side. Mean midline shift was $2.7 \pm 1.5 \mathrm{~mm}$.

Before surgery 49 (50\%) patients had hemiparesis which decreased to $39.8 \%, 24.5 \%, 19.4 \%$ respectively in $1 \mathrm{st}, 7$ th and 30 th post-operative days $(\mathrm{p}=0.001)$.

After the drainage of cSDH, post-operative Medical Research Council (MRC) score of patients significantly improved from 2.7 preoperatively to $3.4,3.9$ and 4.2 respectively in 1 st, 7 th and 30 th post-operative day $(\mathrm{p}=0.001)$.

Pre-operative mean midline shift was $2.7 \mathrm{~mm}$ which decreased to $1.6,0.6$ and $0.2 \mathrm{~mm}$ respectively in 1st, 7th and 30th post-operative days ( $\mathrm{p}$ value 0.001 ).

Irrespective of insertion of drainage system, there was no significant difference noted in recurrence of cSDH in 1 st ( $p$ value 0.38 ), 7th ( $p$ value 0.49 ) or 30th ( $\mathrm{p}$ value 0.14 ) day. Overall recurrence was $14 \%$ vs $16 \%$ with the placement of drain. No significant difference was observed in the midline shift between two groups in 1st ( $\mathrm{p}$ value 0.94$), 7$ th ( $\mathrm{p}$ value 0.53 ) and 30th ( $\mathrm{p}$ value 0.64 ) postoperative day.No significant difference was observed in the improvement in symptoms (hemiparesis or monoparesis) between the two groups in all post-operative days.

Table 2.1 Comparison of recurrence according to placement of drainage

\begin{tabular}{|c|c|c|c|c|c|c|}
\hline \multirow{2}{*}{ Sno. } & \multirow{2}{*}{ Post op days } & \multirow{2}{*}{ Drain } & \multicolumn{2}{|c|}{ Recurrence } & \multirow{2}{*}{ Chi square value } & \multirow{2}{*}{$P$ value } \\
\hline & & & $\mathbf{n}$ & $\%$ & & \\
\hline \multirow{2}{*}{1.} & \multirow{2}{*}{$1 \mathrm{st}$} & No & 16 & 16.3 & \multirow{2}{*}{1.9} & \multirow{2}{*}{0.38} \\
\hline & & Yes & 12 & 12.2 & & \\
\hline \multirow{2}{*}{2} & \multirow{2}{*}{ 7th } & No & 5 & 5.1 & \multirow{2}{*}{1.4} & \multirow{2}{*}{0.49} \\
\hline & & Yes & 4 & 4.1 & & \\
\hline \multirow{2}{*}{3.} & \multirow{2}{*}{ 30th } & No & 2 & 2.0 & \multirow{2}{*}{2.2} & \multirow{2}{*}{0.14} \\
\hline & & Yes & 6 & 6.1 & & \\
\hline
\end{tabular}


Sapkota $S$ et al.

Table 2.2 Comparison of postoperative midline shift according to placement of drainage

\begin{tabular}{|c|c|c|c|c|c|c|}
\hline \multirow{2}{*}{ Sno. } & \multirow{2}{*}{ Post op days } & \multicolumn{2}{|c|}{ Postoperative midline shift } & \multirow[b]{2}{*}{ SD } & \multirow{2}{*}{ t- test value } & \multirow{2}{*}{$P$ value } \\
\hline & & Drain & Mean & & & \\
\hline \multirow{2}{*}{1.} & \multirow{2}{*}{ 1st } & No & 1.6 & 1.4 & \multirow{2}{*}{0.08} & \multirow{2}{*}{0.94} \\
\hline & & Yes & 1.6 & 1.2 & & \\
\hline \multirow{2}{*}{2.} & \multirow{2}{*}{ 7th } & No & 0.7 & 1.0 & \multirow{2}{*}{0.65} & \multirow{2}{*}{0.52} \\
\hline & & Yes & 0.6 & 0.9 & & \\
\hline \multirow{2}{*}{3.} & \multirow{2}{*}{$30^{\text {th }}$} & No & 0.2 & 0.5 & \multirow{2}{*}{0.47} & \multirow{2}{*}{0.64} \\
\hline & & Yes & 0.2 & 0.4 & & \\
\hline
\end{tabular}

Table 2.5: Comparison of postoperative MRC grade (muscle power) according to placement of drainage

\begin{tabular}{|c|c|c|c|c|c|c|}
\hline \multirow{2}{*}{ Sno. } & \multirow[t]{2}{*}{ Post op days } & \multicolumn{3}{|l|}{ MRC score } & \multirow[t]{2}{*}{ t- test value } & \multirow[t]{2}{*}{$P$ value } \\
\hline & & Drain & Mean & SD & & \\
\hline \multirow{2}{*}{1.} & 1st & No & 3.5 & 1.5 & 0.7 & 0.45 \\
\hline & & Yes & 3.2 & 1.7 & & \\
\hline \multirow{2}{*}{2.} & 7th & No & 4.1 & 1.4 & 1.1 & 0.28 \\
\hline & & Yes & 3.7 & 1.7 & & \\
\hline \multirow{2}{*}{3.} & $30^{\text {th }}$ & No & 4.5 & 1.1 & 1.5 & 0.13 \\
\hline & & Yes & 4.0 & 1.7 & & \\
\hline
\end{tabular}

\section{Discussion}

Chronic subdural hematoma is a common disorder that neurosurgeons face in daily practice. It is usually treated surgically. The incidence of cSDH is higher in elderly patients. ${ }^{1}$ Various method have been implemented including burr hole drainage with or without external drainage to twist drill craniostomy to craniotomy and excision of subdural membrane..$^{2,3,7}$ Burrhole drainage has been the most popular and widely accepted form of treatment. Recurrence of cSDH after burr hole drainage has been a significant complication. Recurrence rate varies from 5\% to as high as 30\% between various techniques of sugery. ${ }^{1,3,7}$ Various methods have been practiced to reduce the rate of recurrence; insertion of postoperative subdural drain being one of them. ${ }^{3}$ Most papers show decreased incidence of recurrence with the use of 32 postoperative subdural drain against a slight increase in subdural infection. ${ }^{3,8}$

Our study did not show a statistically significant reduction in recurrence rate with the use of external drainage (14\%vs 16\%). The evidence for recurrence rate and use of drain is not consistent in literature. Wakai and coworkers reported recurrence rates of $5 \%$ vs $33 \%$ for drain and no drain group. ${ }^{9}$ Tatsumi et al reported rates of $3.1 \%$ vs $17 \%$ respectively. ${ }^{10}$ For Lind et al it was $10 \%$ for drain and $19 \%$ for no drain groups. ${ }^{11}$ Sanitarius et al reported recurrence in $9.3 \%$ with drain and $24 \%$ without drain which was statistically significant $(\mathrm{p}=0.003) .{ }^{12}$ Roka et al operated all cases $(n=333)$ with single burr hole and a sub periosteal drain and had recurrence in 4 cases only. ${ }^{13}$ On the other hand Yogi et al operated all the cases without a drain and had recurrence of $5 \% .{ }^{14}$

egneuro, Volume 02,Issue 01, 2020 
Table 2.3: Comparison of post op hemiparesis according to placement of drainage

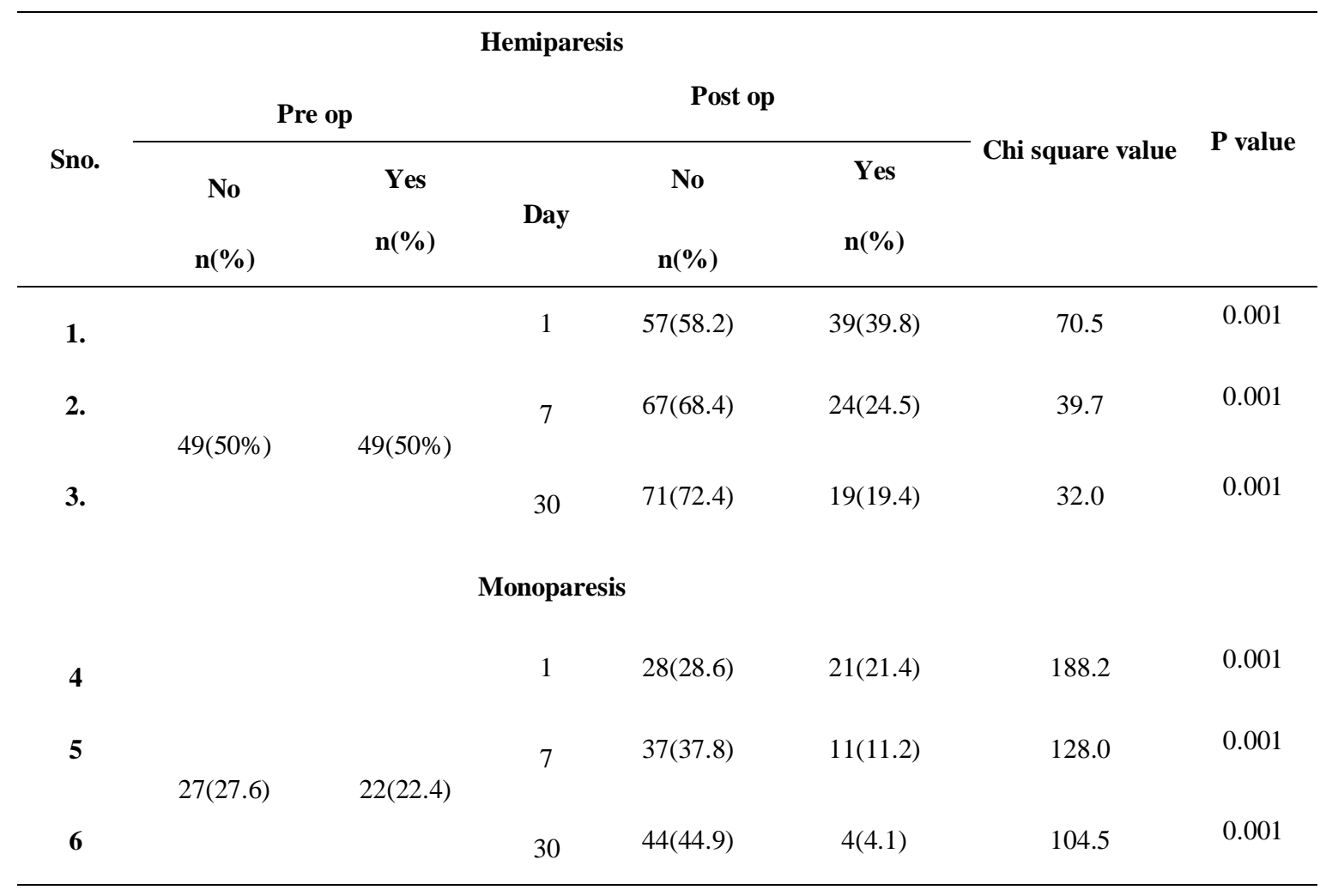

Table 2.6: Comparison of postoperative MRC grade after evacuation of SDH

\begin{tabular}{|c|c|c|c|c|c|c|c|}
\hline \multirow{3}{*}{ Sno. } & \multicolumn{5}{|c|}{ MRC score } & \multirow{3}{*}{$\begin{array}{l}\text { Correlation } \\
\text { coefficient }\end{array}$} & \multirow{3}{*}{$P$ value } \\
\hline & \multicolumn{2}{|c|}{ Pre op } & \multicolumn{3}{|c|}{ Post op } & & \\
\hline & Mean & SD & Day & Mean & SD & & \\
\hline 1. & \multirow[b]{3}{*}{2.7} & \multirow[b]{3}{*}{1.7} & 1 & 3.4 & 1.6 & 0.9 & 0.001 \\
\hline 2. & & & 7 & 3.9 & 1.6 & 0.7 & 0.001 \\
\hline 3. & & & 30 & 4.2 & 1.5 & 0.6 & 0.001 \\
\hline \multicolumn{8}{|c|}{ Midline shift (mm) } \\
\hline 1. & & & 1 & 1.6 & 1.3 & 0.9 & 0.001 \\
\hline 2. & \multirow[b]{2}{*}{2.7} & \multirow[b]{2}{*}{1.5} & 7 & 0.6 & 0.9 & 0.5 & 0.001 \\
\hline 3. & & & 30 & 0.2 & 0.4 & 0.2 & 0.001 \\
\hline
\end{tabular}

In most centers the recurrence of hematoma is often attributed to the post-operative CT scan findings. ${ }^{11}$ However if we consider the pathophysiology of chronic subdural hematoma, the resolution of chronic subdural membrane and egneuro Volume 02, Issue 01, 2020 midline shift takes weeks to months. ${ }^{8,11,13}$ Complete resolution of symptoms is also not immediate. In this setting of residual symptoms and CT findings showing persistent hematoma and midline shift, most surgeons would consider recurrence and 
undertake repeat drainage. So, recurrence should only be considered when there is worsening of symptoms or at least when there is no improvement despite optimal management. Generously large burr hole, meticulous washing of subdural cavity, and repeat drainage only when the patient is not improving or worsening will reduce the recurrence of chronic subdural hematoma. This will reduce the recurrence, avoid placement of subdural drains and hence the complications related to its placement.

\section{Conclusion}

Considerable proportion of patients treated surgically for cSDH presented with postoperative recurrence. Burr hole drainage of chronic subdural hematoma led to improvement in conscious level as well as weakness of limbs irrespective of placement of external drainage. There was no statistically significant difference in recurrence or MRC improvement or midline shift between two groups with or without postoperative subdural drain.

\section{Disclosure:}

This study was done as a part of thesis for partial fulfillment of Masters of Neurosurgery degree awarded by King Edward Medical University to Dr Suresh Sapkota, the primary author of this article.

\section{References}

1. Arbit E, Patterson Jr RH, Fraser RA. An implantable subdural drain for treatment of chronic subdural hematoma. Surgical neurology. 1981 Mar 1;15(3):175-7.

2. Araujo JF, Garcia-Iafigliola M, Jose-Balbo R: [Chronic subdural hematoma: Analysis of 35 cases]. Arquivos de Neuro-Psiquiatria (in Portuguese). 1996;54:71-74.

3. Asano Y, Hasuo M, Takahashi I, Shimosawa S. Recurrent cases of chronic subdural hematoma--its clinical review and serial CT findings. No to shinkei= Brain and nerve. 1992 Sep;44(9):827-31.

4. Ernestus RI, Beldzinski P, Lanfermann H, Klug N. Chronic subdural hematoma: surgical treatment and outcome in 104 patients. Surgical neurology. 1997 Sep 1;48(3):220-5.

5 Fukuhara T, Gotoh M, Asari S, Ohmoto T, Akioka T. The relationship between brain surface elastance and brain reexpansion after evacuation of chronic subdural hematoma. Surgical neurology. 1996 Jun;45(6):570-4.
6. ITO H, KOMAI T, YAMAMOTO S. Fibrin and fibrinogen degradation products in chronic subdural hematoma. Neurologia medico-chirurgica. 1975;15(1):51-5.

7. Krupp WF, Jans PJ. Treatment of chronic subdural haematoma with burr-hole craniostomy and closed drainage. British journal of neurosurgery. 1995 Jan 1;9(5):619-28.

8. Markwalder TM, Seiler RW. Chronic subdural hematomas: to drain or not to drain?. Neurosurgery. 1985 Feb 1;16(2):1858 .

9. Wakai S, Hashimoto $\mathrm{K}$, Watanabe $\mathrm{N}$, Inoh S, Ochiai $\mathrm{C}$, Nagai M. Efficacy of closed-system drainage in treating chronic subdural hematoma: a prospective comparative study. Neurosurgery. 1990 May 1;26(5):771-3.

10. Tsutsumi K, Maeda K, Iijima A, Usui M, Okada Y, Kirino $\mathrm{T}$. The relationship of preoperative magnetic resonance imaging findings and closed system drainage in the recurrence of chronic subdural hematoma. Journal of neurosurgery. 1997 Dec 1;87(6):870-5.

11. Lind CR, Lind CJ, Mee EW. Reduction in the number of repeated operations for the treatment of subacute and chronic subdural hematomas by placement of subdural drains. Journal of neurosurgery. $2003 \mathrm{Jul}$ 1;99(1):44-6.

12. Santarius T, Lawton R, Kirkpatrick PJ, Hutchinson PJ. The management of primary chronic subdural haematoma: a questionnaire survey of practice in the United Kingdom and the Republic of Ireland. British journal of neurosurgery. 2008 Jan 1;22(4):529-34.

13. Roka YB, Firoj A, Alok J, Biprav L. Single Burr Hole and Drainage in Chronic Subdural Hematoma: Outcome in Consecutive 333 Cases. Nepal Journal of Neuroscience. 2016 Oct 9;13(1):35-42.

14. Yogi N, Nepal PR, Gongal DN, Devkota UP. Analysis of risk factors predicting recurrence of chronic subdural hematoma. Nepal Journal of Neuroscience. 2018 Dec 31;15(3):32-8. 